\title{
Transvaginal sonography versus saline contrast sonohysterography in evaluation of abnormal uterine bleeding
}

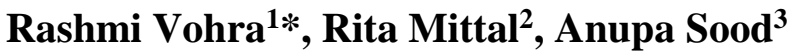

\begin{abstract}
${ }^{1}$ Department of Obstetrics and Gynecology, MM Medical College Mullana, Ambala, Haryana, India
${ }^{2}$ Department of Obstetrics and Gynecology, IGMC Shimla, Himachal Pradesh, India

${ }^{3}$ Department of Obstetrics and Gynecology, MM Medical College, Solan, Himachal Pradesh, India
\end{abstract}

Received: 21 July 2017

Revised: 05 August 2017

Accepted: 22 August 2017

\section{*Correspondence:}

Dr. Rashmi Vohra,

E-mail: rashmivohra99@gmail.com

Copyright: (c) the author(s), publisher and licensee Medip Academy. This is an open-access article distributed under the terms of the Creative Commons Attribution Non-Commercial License, which permits unrestricted non-commercial use, distribution, and reproduction in any medium, provided the original work is properly cited.

\section{ABSTRACT}

Background: To evaluate TVS and SCSH as a screening method in case of AUB and to correlate he findings of TVS and SCSH with hysterectomy specimen.

Methods: Present study was conducted in department of obstetrics and gynaecology, Kamla Nehru Hospital for mother and child, IGMC, Shimla for a period of one year. A total of 150 patients with AUB were subjected to TVS and SCSH in same sitting irrespective of their phase of menstrual cycle. All the cases were subjected to hysterectomy within 2 weeks and operative findings were noted. Data was collected and findings analysed.

Results: Overall sensitivity of SCSH was found to be $97.6 \%$ while that of TVS was $95.1 \%$. The overall specificity of SCSH was found to be $99.6 \%$ and that of TVS was $98.2 \%$. PPV, NPV and DA for SCSH was more than that of TVS i.e., $98.9 \%$ vs $97.4 \%, 99.7 \%$ vs $99.3 \%$ and $99.4 \%$ vs $98.7 \%$.

Conclusions: SCSH represents a new and promising technique for investigation of the uterine cavity. It is safe, minimally invasive, easy, cost effective and reliable method to diagnose the cause of AUB.

Keywords: AUB, SCSH, Sensitivity, Specificity, TVS

\section{INTRODUCTION}

Abnormal uterine bleeding accounts for $15 \%$ of office visits and almost $25 \%$ of gynecological surgeries. ${ }^{1}$ AUB can be caused by a variety of uterine abnormalities such as polyp, submucous myoma, endometrial hyperplasia and endometrial carcinoma. ${ }^{2}$ Most commonly used modalities to assess anatomic causes of AUB have been endometrial biopsy, D and C, HSG, TVS and hysteroscopy. In cases where intracavitary masses or submucous myomas are suspected, hysteroscopy has become the most definitive method for diagnosis. ${ }^{3}$ Though hysteroscopy has been considered as gold standard for evaluating the uterine cavity abnormalities, it is invasive, expensive, associated with complications like perforation, embolism, ascending genitourinary infection and cannot asses the myometrial and adnexal pathology. ${ }^{4}$ When TVS was combined with saline contrast in the uterine cavity, the diagnostic accuracy was markedly improved and was found to equal that of hysteroscopy when performed by skilled investigators. ${ }^{5,6}$

SCSH is the term used for ultrasound imaging of uterine cavity, using sterile saline solution as a negative contrast medium. SCSH is a low-tech, low-cost, painless enhancement of TVS which obviates the need for diagnostic hysteroscopy in cases of AUB. SCSH can detect focal pathology and suggest the diagnosis of an 
endometrial polyp or a submucosal fibroid on the basis of the echotexture and, in cases of fibroids or adenomyosis, the presence of overlying endometrium. Blood clots and synechiae may also result in apparent endometrial thickening, but SCSH can usually differentiate between these findings and diffuse endometrial hyperplasia.

The objective of the study was to evaluate TVS and SCSH as a screening method in cases of AUB. To correlate the findings of TVS and SCSH with hysterectomy specimen.

\section{METHODS}

A total of 150 patients who presented with complaint of AUB were admitted for hysterectomy in the Department of Obstetrics and Gynaecology, KNSH M\&C IGMC Shimla from the year 2011 to 2012.

\section{Inclusion criteria}

- Premenopausal status; defined as no more than 12 months amenorrhoea,

- Uterus less than 12-week size.

\section{Exclusion criteria}

- Uterus more than 12-week size,

- Acute pelvic infection,

- Acute uterine hemorrhage,

- Suspected or diagnosed cases of genital cancer,

- Pregnancy,

- Serious cardiopulmonary diseases,

- Cervical cytology on speculum examination/ abnormal Pap smear.

Detailed history, GPE and laboratory investigations were done on all 150 patients included in the study. Then all patients were subjected to TVS irrespective of their phase of menstrual cycle.

TVS machine which was used was Toshiba Test Vision200, with $6.5 \mathrm{~Hz}$ transvaginal probe. The contour of endometrial cavity was studied in longitudinal and transverse plane and uterine pathology and endometrial thickness were noted. Endometrial thickness more than or equal to $12 \mathrm{~mm}$ was taken as significant and labelled as endometrial hyperplasia.

All cases were then subjected to SCSH in same sitting. Tablet buscopan was given half an hour before doing SCSH. No. 8 Foleys catheter was introduced into uterine cavity.

Bulb was inflated with $3 \mathrm{cc}$ of normal saline and mild traction was given so as to place the bulb at the level of internal os. Vaginal probe was then introduced. Sterile saline was infused until distention of uterine cavity was adequate to see any lesions or till pain appears.
Amount of normal saline infused, appearance of pain or any other complications were noted. Multiple sagittal and coronal images were obtained and findings were noted. All the cases were subjected to hysterectomy within 2 weeks and operative findings were noted. Findings at TVS and SCSH were compared with findings of hysterectomy specimen.

Findings were analysed and sensitivity, specificity, positive predictive value, negative predictive value and diagnostic accuracy were calculated.

\section{RESULTS}

A total of 150 patients who presented with AUB and were admitted for hysterectomy in the Department of Obstetrics and Gynaecology, KNSH M and C IGMC Shimla were included in the study which was conducted from May 2011 to June 2012. In all 150 cases, the findings of TVS were compared with SCSH. Table 1 shows the comparative diagnosis on TVS and SCSH.

Table 1: Shows the comparative diagnosis on TVS and SCSH.

\begin{tabular}{|lll|}
\hline Findings & TVS & SCSH \\
\hline Normal study & 31 & 30 \\
\hline Endometrial hyperplasia & 39 & 39 \\
\hline Intramural fibroid & 44 & 43 \\
\hline Submucosal fibroid & 16 & 18 \\
\hline Endometrial polyp & 12 & 13 \\
\hline Subserosal fibroid & 06 & 06 \\
\hline Adenomyosis & 02 & 01 \\
\hline
\end{tabular}

All the patients were operated upon and per-operative anatomical features were noted with full details as shown in Table 2.

Table 2: All the patients were operated upon and peroperative anatomical features.

\begin{tabular}{|lll|}
\hline Operative finding & Numbers & $\%$ \\
\hline Normal study & 30 & 20.0 \\
\hline Endometrial hyperplasia & 37 & 24.7 \\
\hline Intramural fibroid & 42 & 28.0 \\
\hline Submucosal fibroid & 20 & 13.3 \\
\hline Endometrial polyp & 14 & 9.3 \\
\hline Subserosal fibroid & 06 & 4.0 \\
\hline Adenomyosis & 01 & 0.7 \\
\hline Total & 150 & 100.0 \\
\hline
\end{tabular}

Various values of true positive, true negative, false positive, false negative for both TVS as well as SCSH are shown in Tables 3. Overall sensitivity of SCSH was found to be $97.6 \%$ while that of TVS was $95.1 \%$. The overall specificity of SCSH was found to be $99.6 \%$ and that of TVS was $98.2 \%$. PPV, NPV and DA for SCSH was more than that of TVS i.e., $98.9 \%$ vs $97.4 \%, 99.7 \%$ vs $99.3 \%$ and $99.4 \%$ vs $98.7 \%$. 
Table 3: Comparative table for TVS and SCSH.

\begin{tabular}{|lllllllllll|l|} 
& \multicolumn{2}{c}{ Sensitivity \% } & Specificity \% & PPV $\%$ & \multicolumn{2}{c|}{ NPV \% } & DA \% \\
& TVS & SCSH & TVS & SCSH & TVS & SCSH & TVS & SCSH & TVS & SCSH \\
\hline NS & 100 & 100 & 99.2 & 100 & 96.8 & 100 & 100 & 100 & 99.3 & 100 \\
\hline EH & 100 & 100 & 98.1 & 98.2 & 95.5 & 94.9 & 100 & 100 & 98.7 & 98.7 \\
\hline IMF & 100 & 100 & 98.1 & 99.1 & 95.5 & 97.7 & 100 & 100 & 98.7 & 99.3 \\
\hline SMF & 80.0 & 90.0 & 100 & 100 & 100 & 100 & 97.0 & 98.5 & 97.3 & 98.7 \\
\hline EP & 85.7 & 92.9 & 92.9 & 100 & 100 & 100 & 98.5 & 99.3 & 98.7 & 99.3 \\
\hline SSF & 100 & 100 & 100 & 100 & 100 & 100 & 100 & 100 & 100 & 100 \\
\hline Adenomyosis & 100 & 100 & 99.3 & 100 & 50.0 & 100 & 99.3 & 100 & 98.3 & 100 \\
\hline
\end{tabular}

\section{DISCUSSION}

Abnormal uterine bleeding is a common but complicated clinical presentation, diagnosis of which is often variable. Small intracavitary lesions are often missed on routine TAS. TVS has emerged a better method for imaging uterine and endometrial anomalies, but small structural anomalies can be missed and endometrial and myometrial anomalies cannot always be differentiated. ${ }^{6}$

SCSH represents a new and promising technique for investigation of the uterine cavity. It is safe, minimally invasive, easy, cost effective and reliable method to diagnose the cause of AUB. ${ }^{6}$

Table 4: Sensitivity and specificity of TVS versus SCSH in various studies.

\begin{tabular}{|c|c|c|c|c|}
\hline Study & Year & Procedure & Sensitivity \% & Specificity \% \\
\hline \multirow{2}{*}{ Schwarzler $\mathrm{P}$ et $\mathrm{al}^{9}$} & \multirow{2}{*}{1998} & TVS & 67.0 & 89.0 \\
\hline & & SCSH & 87.0 & 91.0 \\
\hline \multirow{2}{*}{ Dijkhuizen FPHLJ et al ${ }^{10}$} & \multirow{2}{*}{2000} & TVS & 61.0 & 96.0 \\
\hline & & SCSH & 100 & 85.0 \\
\hline \multirow{2}{*}{ Guven MA et al ${ }^{11}$} & \multirow{2}{*}{2004} & TVS & 56.0 & 68.0 \\
\hline & & SCSH & 81.0 & 73.0 \\
\hline \multirow{2}{*}{ Ryu J et al ${ }^{12}$} & \multirow{2}{*}{2004} & TVS & 79.0 & 46.0 \\
\hline & & SCSH & 95.0 & 83.0 \\
\hline \multirow{2}{*}{ Aslam $\mathrm{M}$ et al ${ }^{13}$} & \multirow{2}{*}{2007} & TVS & 71.4 & 67.7 \\
\hline & & SCSH & 92.9 & 89.7 \\
\hline \multirow{2}{*}{ Kim SJ et al ${ }^{14}$} & \multirow{2}{*}{2009} & TVS & 85.5 & 68.9 \\
\hline & & SCSH & 94.7 & 82.8 \\
\hline \multirow{2}{*}{ Reddi RP et $\mathrm{al}^{4}$} & \multirow{2}{*}{2010} & TVS & 65.5 & 63.6 \\
\hline & & SCSH & 82.0 & 83.3 \\
\hline \multirow{2}{*}{ Present study } & \multirow{2}{*}{2012} & TVS & 95.1 & 98.2 \\
\hline & & SCSH & 97.6 & 99.6 \\
\hline
\end{tabular}

Table 5: PPV, NPV, and DA of TVS versus SCSH in various studies.

\begin{tabular}{|c|c|c|c|c|c|}
\hline Study & Year & Procedure & PPV \% & NPV \% & DA \% \\
\hline \multirow{2}{*}{ Schwarzler $\mathrm{P}$ et $\mathrm{al}^{9}$} & \multirow{2}{*}{1998} & TVS & 88.0 & 71.0 & - \\
\hline & & SCSH & 92.0 & 86.0 & - \\
\hline \multirow{2}{*}{ Epstein E et al ${ }^{15}$} & \multirow{2}{*}{2001} & TVS & 64.0 & 69.0 & 68.0 \\
\hline & & SCSH & 70.0 & 83.0 & 77.0 \\
\hline \multirow{2}{*}{ Guven MA et al ${ }^{11}$} & \multirow{2}{*}{2004} & TVS & 75.0 & 78.0 & - \\
\hline & & SCSH & 83.0 & 70.0 & - \\
\hline \multirow{2}{*}{ Ryu J et al ${ }^{12}$} & \multirow{2}{*}{2004} & TVS & 83.0 & 39.0 & - \\
\hline & & SCSH & 95.0 & 83.0 & - \\
\hline \multirow{2}{*}{ Aslam $\mathrm{M}$ et al ${ }^{13}$} & \multirow{2}{*}{2007} & TVS & 54.4 & 81.5 & 69.0 \\
\hline & & SCSH & 86.7 & 94.5 & 91.0 \\
\hline \multirow{2}{*}{ Kim SJ et al ${ }^{14}$} & \multirow{2}{*}{2009} & TVS & 87.8 & 64.5 & 80.9 \\
\hline & & SCSH & 93.5 & 85.7 & 91.4 \\
\hline \multirow{2}{*}{ Reddi RP et al ${ }^{4}$} & \multirow{2}{*}{2010} & TVS & 68.0 & 90.0 & - \\
\hline & & SCSH & 81.0 & 93.0 & - \\
\hline \multirow{2}{*}{ Present study } & \multirow{2}{*}{2012} & TVS & 97.4 & 99.3 & 98.7 \\
\hline & & $\mathrm{SCSH}$ & 98.9 & 99.7 & 99.4 \\
\hline
\end{tabular}




\section{CONCLUSION}

To conclude, the overall sensitivity of SCSH was found to be $97.6 \%$ while that of TVS was $95.1 \%$. The overall specificity of SCSH was found to be $99.6 \%$ and that of TVS was $98.2 \%$.

Thus, the sensitivity and specificity was more for SCSH. PPV, NPV and DA for SCSH was more than that of TVS i.e., $98.9 \%$ vs $97.4 \%, 99.7 \%$ vs $99.3 \%$ and $99.4 \%$ vs $98.7 \%$. SCSH is especially helpful for intracavitary abnormalities. So TVS could be supplemented with SCSH for better diagnosis.

Funding: No funding sources

Conflict of interest: None declared

Ethical approval: The study was approved by the Institutional Ethics Committee

\section{REFERENCES}

1. Laughead MK, Stones LM. Clinical utility of saline solution infusion sonohysterography in a primary care obstetric-gynecologic practice. Am J Obstet Gynecol. 1997;176(6):1313-6.

2. Karimzadeh $\mathrm{MH}$, Firouzabadi RD, Goharzad F. Diagnostic value of saline contrast sonohysterography comparing with hysteroscopy for detecting endometrial abnormalities in women with abnormal uterine bleeding. Iranian Journal of Reproductive Medicine. 2011;9(3):199-202.

3. Williams CD, Marshburn PB. A prospective study of transvaginal hydrosonography in the evaluation of abnormal uterine bleeding. Am J Obstet Gynecol. 1998;179:292-8.

4. Reddi RP, Lakshmikantha G. Transvaginal sonography and saline infusion sonohysterography in the evaluation of abnormal uterine bleeding. J Obstet Gynecol India. 2010;60(6):511-15.

5. Bronz L, Suter T, Rusca T. The value of transvaginal sonography with and without saline instillation in the diagnosis of uterine pathology in pre- and postmenopausal women with abnormal bleeding or suspect sonographic findings. Ultrasound Obstet Gynecol. 1997;9:53-8.

6. Parsons AK. Lense JJ. Sonohysterography for endometrial abnormalities: preliminary results. J Clin Ultrasound. 1993;21:87-95.

7. Dueholm M, Forman A, Jensen ML, Laursen H, Kracht P. Transvaginal sonography combined with saline contrast sonohysterography in evaluating the uterine cavity in premenopausal patients with abnormal uterine bleeding. Ultrasound Obstet Gynecol. 2001;18(1):54-61.

8. Rudra S, Duggal BS, Bharadwaj D. Prospective Study of Saline Infusion Sonography and Office Hysteroscopy. MJAFI. 2009;65:332-5.

9. Schwarzler P, Concin H, Bosch H. An evaluation of sonohysterography and diagnostic hysteroscopy for the assessment of intrauterine pathology. Ultrasound Obstet Gynecol. 1998;11:337-42.

10. Dijkhuizen FP, de Vries LD, Mol BW, Brolmann HA, Peters HM, Moret E, et al. Comparison of transvaginal ultrasonography and saline infusion sonography for the detection of intracavitary abnormalities in premenopausal women. Ultrasound Obstet Gynecol. 2000;15:372-6.

11. Guven MA, Bese T, Demirkiran F. Comparison of hydrosonography and transvaginal ultrasonography in the detection of intracavitary pathologies in women with abnormal uterine bleeding. Int J Gyneco Cancer. 2004;14(1):57-63.

12. Ryu J, Kim B, Lee J, Kim S, Lee SH. Comparison of transvaginal ultrasonography with hysterosonography as a screening method in patients with abnormal uterine bleeding. Korean J Radiol. 2004;5:39-46.

13. Aslam M, Ijas L, Tariq S, Shafqat K, Nisa M, Ashraf A, Kazmi T. Comparison of transvaginal sonography and saline contrast sonohysterography in women with abnormal uterine bleeding: Correlation with hysteroscopy and histopathology. International Journal of Health Sciences, Qassim University 2007;1(1):17-24.

14. Kim S, Rhim C. The value of transvaginal sonography and sonohysterography in the determination of the cause of abnormal uterine bleeding. J of Women's Medicine. 2009;2(2):70-7.

15. Epstein E, Ramirez A, Skoog L, Valentin L. Transvaginal sonography, saline contrast sonohysterography and hysteroscopy for the investigation of women with postmenopausal bleeding and endometrium $>5 \mathrm{~mm}$. Ultrasound in Obstet Gynecol. 2001;18:157-62.

Cite this article as: Vohra R, Mittal R, Sood A. Transvaginal sonography versus saline contrast sonohysterography in evaluation of abnormal uterine bleeding. Int J Reprod Contracept Obstet Gynecol 2017;6:4437-40. 